\title{
SKELETAL FLUOROSIS- AN EPIDIMIO-CLINICO-RADIOLOGICAL STUDY
}

Prasanta Kumar Mandal, Dibakar Ray, Fagu Ram Majhi, Somnath Tirkey, Mrinal Kanti Ray, Surajit Mondal.

1. Associate Professor. Department of Orthopaedics, Bankura Sammilani Medical College \& Hospital.

2. Assistant Professor. Department of Orthopaedics, Bankura Sammilani Medical College \& Hospital.

3. Assistant Professor. Department of Orthopaedics, Bankura Sammilani Medical College \& Hospital.

4. Junior Resident, Department of Orthopaedics, Bankura Sammilani Medical College \& Hospital.

5. Assistant Professor. Department of Orthopaedics, Bankura Sammilani Medical College \& Hospital.

6. Junior Resident. Department of Orthopaedics, Bankura Sammilani Medical College \& Hospital.

\section{CORRESPONDING AUTHOR}

Dr. Prasanta Kumar Mandal,

Vill. Lokepur, P.O. Kenduadihi,

Bankura- 722102.

E-mail: drprasantamondal@gmail.com

Ph: 00919434173124.

ABSTRACT: Skeletal fluorosis is endemic problem in many parts of world including India as well as West Bengal effecting mainly low socio-economic group of populations. This study is to detect the epidemiological and clinical as well as radiological survey to detect and help to prevent the morbidity and mortality of the people from the so called slow environmental poison.

KEYWORDS: - Skeletal Fluorosis, Radiological Study, Epidemiological study, clinical study

IN TRODUCTION : Fluorine is the most abundant element in nature ${ }^{1}$. It occurs naturally in the Earth's crust, water and food as the negatively charged ion fluoride (F). Fluorine is considered to be a trace element because only small amounts are present in the body (about 2.6 gm in adult), and because the daily requirement for maintaining health is only a few milligrams a day. About $96 \%$ of total body fluoride is found in the bones and teeth ${ }^{3,5}$. Although its role in the prevention of dental caries (tooth decay) is well established ${ }^{6}$, fluoride is not generally considered an essential mineral element because humans do not require it for growth or to sustain life. However, if one considers the prevention of chronic diseases (dental caries, osteoporosis), an important criterion in determining essentiality, then fluoride might well be considered an essential trace element ${ }^{7}$.

MATERIALS AND METHODS: The Subject: The study was carried out on the patients after admission in the department of orthopaedics, Bankura Sammilkani Medical College and Hospital during the year August 2009 to April 2012.

The Case: An exclusive epidemioclinical survey was done in July 2000 in the village-Nashipur of Birbhum district. The total population including all age groups and sex of the Nashipur village was covered during the survey. From there, 31 patients chosen by systematic random sampling, was admitted in the department of orthopaedics and prospective and retrospective study was done. All skeletal fluorosis cases apparently detected by clinical examination were confirmed by haematological, Biochemical, radiological and pathological investigations. 
The Control: A control village Bhabanandapur $5 \mathrm{~km}$ away from Nashipur, having all the matching characteristics excepting the skeletal fluorosis was considered for the same study also in order to make valid comparison between the two groups there are sixty patients chosen by systematic random sampling to isolate the aetiological factors towards the development of the disease.

Therefore at the time of study the following issues were considered: ---

1. Epidemio-clinical study was case control (Analytical) in nature.

2. Both skeletal and dental fluorosis was detected clinical in initial time.

3. Fluoride content of water in both the villages (i.e. - Nashipur and Bhabanadapur) was determined by Dept. of Chemistry Burdwan University and that was 12-15 ppm and <.8 ppm respectively.

Thirty one cases of both sex and with all age group of skeletal fluorosis were registered for study. Each patient was subjected to thorough history and detailed examination with special emphasis on skeletal system.

A detailed history of duration of exposure or migration, occupation complain of back pain, joint pain, leg pain, stiffness of spine or any other joints, deformity, breathing difficulty, weakness on limbs was taken.

Each patient was examined thoroughly for any anemia, jaundice, oedema, and chest expansion and mottling.

Thorough examination of spine for kyphosis, tenderness of spinous processes, paraspinal tenderness, nodule, restriction of movements and also each and every joints of both upper limb and lower limb examined for deformity, muscular wasting, tenderness and movements.

The diagnosis was confirmed by clinical, biochemical (fluoride level in blood and bone) radiological and pathological investigations.

The correction of deformity such as genu valgus or genu varus, and preventive measures to inhibit progression of disease to be taken accordingly.

RESULTS: Present study was conducted on 31 skeletal fluorosis patient and 60 properly matched control patients.

AGE: Youngest patient in this present series was a male aged 8 years and oldest patient in this series was a male of 70 years. The maximum no. of patient is in between $8-20$ years $32.25 \%$. Average age of the patient was 34.67 years.

In this study group male out numbers females the total percentage for male was $70.97 \%$, and for female it was $29.03 \%$.

Male: Female ratio is $2.4: 1$

DISCUSSION: Thirty one patients with all age group and both sexes of skeletal fluorosis selected by systematic random sampling in an epidemiological survey at Nashipur village of Birbhum district- admitted in the department of Calcutta National Medical Colleges and Hospital, B. S. Medical College \& Hospital, Bankura, Burdwan Medical College and Hospital were taken for this study. Sixty age, sex socioeconomic status and geographic location matched persons admitted in different department of Calcutta National Medical Colleges and Hospital Burdwan Medical College and Hospital with different medical problems were taken as a control group. Fluoride content of drinking water of both the villages was detected. 
Age range of patients was 8-70 years with mean age being 34.67 years. There were 22 male and 9 female patients. All patients of case group used to drink fluoride toxicated water (12-15 ppm) either since birth or since 1978. $45.16 \%$ of the patients were manual labour. $80 \%$ of the patients were used to stay outside the home for working purpose and used to drink more water.

$80.64 \%$ patients were complaining of low back pain, $77 \%$ patients had leg pain or major joint pain, $61.29 \%$ patients had dental fluorosis and $54.83 \%$ patients had great joint stiffness or back stiffness. Chest expansion was diminished $(<3 \mathrm{~cm})$ in $100 \%$ patients, $22.58 \%$ patients had severe anemia without any other medical cause three $(19.35 \%)$ patient had oedema on general survey chest expansion was significantly reduced 14 patients had kyphotic deformity 25 patients had restricted spinal movement and 8 patients had paraspinal tenderness. Restricted elbow movement was found in 14 cases. Fixed flexion deformity of hip was found in 15 cases and restricted hip movement was found in 16 cases.

Fluoride level of blood and bone was increased significantly. On X-ray 24 patients 777.41 $\%$ ) had osteosclerotic changes in their skeleton $22.58 \%$ had mild osteosclerotic changes. All cases were histologically fluorotic.

CONCLUSION: Multicentric study with larger number of patients was necessary to know the nature and extent of the disease and how to handle the problem so that the skeletal fluorosis patient can be managed in better fashion. The study group represents only a portion of fluorosis victims of Nashipur village. The affected villagers have mild to severe skeletal fluorosis. Some of them require symptomatic relief (like deformity correction). A thorough epidemiological survey of Nashipur and adjacent villages are necessary to find out the exact magnitude of the problem and a long term follow-up of post-operative patients are required to dictate the efficiency of surgical treatment applied. All efforts should be given to provide safe drinking water to stop further progress of the disease.

\section{B I B L I O GRA PYHY:}

1. Park's text book of Preventive and Social Medicine, K Park 2010.

2. Text book of orthopaedics and trauma, Kulkarni GS.

3. Cerklewski, F.L. Fluoride bioavailability-nutritional and clinical aspects. Nutrition Research, 1997; Volume 17 : Pages 907-929.

4. Nielson, F.H. Ultratrace minerals. In Sbils, M et. all.. Eds. Nutrition in Health and disease, $9^{\text {th }}$ edition. Baltimore : Williams \& Wilkins, 1999 : Pages 283-303

5. Cerklewski, F.L. Fluoride : essential or just beneficial Nutrition. 1998, Volume 14 : Pages 475-476

6. Institute of Medicine, Food and nutrition Board Dietary reference intakes : calcium, Phosphorus, Magnesium, Vitamin D and Fluoride. Washington DC : National academy press, 1997 : Pages 288-313.

7. Centres for disease control. Achievements in Public Health, 1900-1999 : Fluoridation of drinking water to prevent dental caries. Morbidity and Mortality Weekly Report (MMWR). 1999 : Volume 48 : Pages 933-940

8. Pak, CY. et. al. Treatment postmenopausal osteoporosis with slow release sodium fluoride : Final report of a randomized controlled trial. Annuals of Internal Medicine. 1995; Volume 123 : Pages 401-408of 
9. Murray, T.M. \& Ste-Marie, L-G. Fluoride therapy for osteoporosis. Canadian Medical Association Journal (CMAJ). 1996; Volume 155 : Pages 949-954

10. Susheela, A.K. Prevention and control of fluorosis. Vol-II - Health Aspects. Rajiv Gandhi National drinking water Mission Govt. of India. 1993

11. Whitford, G.M. The metabolism and toxicity of fluoride. In Meyer, H.H. Ed. Monographs in oral Science. Volume 13. Basel (Switzerland) : S. Kangen AG, 1996

12. Susheela, A.K. and Majumdar, K., Guide on water and excreta related disease for grassroot level functionaries IEC 04. Rajiv Gandhi National Drinking water Mission and National Institute of Rural Development. Govt. of India. 1998

13. Jenkins GN, Vankateswarlu P, Zipkin. Physiological effects of small doses of fluoride In : Fluoride and Human health Geneva. World Health Organization, 1970; pp 163-223

14. Public Health Engineering Department Fluoride affected villages. Habitat Survey Rajashthan, PHED, Rajashthan, Jaipur 1991-93 pp 1-21

15. Susheela, A.K. Kumar, A., Bhatnagar, M. and Bhadur, R., Fluoride, 1993; 26, 97-104

16. World Health Organization. Guidelines for drinking water quality, Geneva, Volumes World Health Organization, 1984 : p-249

17. Paramasivam, R. and Nanoti, M.V. Defluoridation and water quality analysis, National environmental Engineering Research Institute, Nagpur, 1997

18. Riggs, B.L. et. al.. effect of fluoride treatment on the fracture rate in postmenopausal women with osteoporosis. The New England Journal of Medicine 1990; Volume 322 : Pages 802-809.

19. Choubisa SL, Sampura K, Bhatt SK, Choubisa DK, Pandya H, Joshi SE, Prevalence of Flurosis in some villages of Dungarpur District of Rajashthan. Indina J Hlth 1996; 38; 119-126.

20. Lehmann, R. et. al.. drinking water fluoridation : bone mineral density and hip fracture incidence. Bone. 1998; Volume 22 : Pages 273-278

Table 1: Proportion of patients belonging to different age groups in both sex.

\begin{tabular}{|c|c|c|c|c|}
\hline \multirow{2}{*}{$\begin{array}{c}\text { Age in } \\
\text { Years }\end{array}$} & \multicolumn{2}{|c|}{ Sex } & Total & Percentage \\
\cline { 2 - 4 } & Male & Female & & \\
\hline $8-20$ & 5 & 5 & 10 & 32.25 \\
\hline $21-30$ & 2 & 1 & 3 & 9.67 \\
\hline $31-40$ & 5 & 2 & 7 & 22.58 \\
\hline $41-50$ & 4 & 1 & 5 & 16.12 \\
\hline $51-60$ & 2 & $\mathrm{x}$ & 2 & 06.45 \\
\hline $61-70$ & 4 & $\mathrm{x}$ & 4 & 12.90 \\
\hline
\end{tabular}


Age :Youngest patient in this present series was a male aged 8 years and oldest patient in this series was a male of 70 years. The maximum no. of patient is in between $8-20$ years $32.25 \%$. Average age of the patient was 34.67 years.

Table 2: Sex distribution

\begin{tabular}{|c|c|c|}
\hline Sex & No of Cases & Percentage \\
\hline Male & 22 & 70.97 \\
\hline Female & 9 & 29.03 \\
\hline
\end{tabular}

In this study group male out numbers females the total percentage for male was $70.97 \%$, and for female it was $29.03 \%$.

Male : Female ratio is $2.4: 1$

Table 3: Distribution of cases according to their occupation.

\begin{tabular}{|c|c|c|}
\hline Occupation & No of Cases & Percentage \\
\hline Student & 7 & 22.58 \\
\hline Labourer & 14 & 45.16 \\
\hline Cultivator & 4 & 12.90 \\
\hline Housewife & 6 & 19.35 \\
\hline
\end{tabular}

The table shows that maximum no. of patients (percentage $45.16 \%$ ) are in the group of labour and who work outside the home and used to drink more water than the student or housewives.

Table 4: Type of Clinical presentation

\begin{tabular}{|c|c|c|c|c|c|}
\hline Sl. No. & Complaints & \multicolumn{2}{|c|}{ No. of Cases } & Total & Percentage \\
\hline & & Male & Female & & \\
\hline 1 & Back Pain & 18 & 7 & 25 & 80.64 \\
\hline 2 & Joint Pain \& leg pain & 16 & 8 & 24 & 77.41 \\
\hline 3 & Stiffness of major joints & 14 & 3 & 17 & 54.83 \\
\hline 4 & Deformity & 7 & 3 & 10 & 32.25 \\
\hline 5 & Neurodeficit & 5 & $\mathrm{X}$ & 5 & 16.12 \\
\hline 6 & Visible Nodule & 12 & $\mathrm{X}$ & 12 & 38.71 \\
\hline 7 & Breathing difficulty & 14 & 4 & 18 & 58.06 \\
\hline 8 & Dental fluorosis & 11 & 8 & 19 & 61.29 \\
\hline
\end{tabular}


Maximum no (25) of patient (percentage 80.64) complaints of low back pain. Neurodeficit including quadriplegia is the rarest complain of this study group (only 16.12\%).

Table 5: Types of abnormality on General Examination

\begin{tabular}{|c|c|c|c|}
\hline Sl. No. & Findings & No. of Cases & Percentage \\
\hline 1 & Gross Anemia & 7 & 22.58 \\
\hline 2 & Jaundice & 1 & 03.2 \\
\hline 3 & Oedema & 6 & 19.35 \\
\hline 4 & Diminished Chest expansion $(<3 \mathrm{~cm})$ & 31 & 100 \\
\hline
\end{tabular}

Diminished chest expansion $<3 \mathrm{~cm}$ is present in $100 \%$ cases Jaundice is present minimally in $3.2 \%$ cases only.

Table 6: Comparison of chest expansion in case and control.

\begin{tabular}{|l|l|l|l|l|l|}
\hline Sl. No. & & No. of cases & Mean (X) & SD & P value \\
\hline 1 & Control & 60 & 5 & 0.5 & $<.001$ \\
\hline 2 & Case & 31 & 1.92 & 0.152 & \\
\hline
\end{tabular}

Calculation : As this study was done with 31 cases and 60 controls

Case No. $\left(\mathrm{n}_{1}\right)=31$

Control No $\left(n_{2}\right)=60$

So standard error is to be calculated by z value

$$
\mathrm{Z}=\frac{\mathrm{X}_{1}-\mathrm{X}_{2}}{\sqrt{\frac{\mathrm{SD}_{1}^{2}}{\mathrm{n}_{1}}+\frac{\mathrm{SD}_{2}^{2}}{\mathrm{n}_{2}}}}
$$

$=\frac{5-1.9290}{\sqrt{\frac{0.25}{60}+\frac{0.023}{31}}}$

$=\frac{3.71}{0.753}=4.076$ from the statistical chart $\mathrm{p}$ value is $<0.001$

So chest expansion in the case group is significantly reduced than the control group. 
Table 7: Comparative study of fluoride level in blood in case and control group

\begin{tabular}{|c|c|c|c|c|}
\hline Sl. No. & & Mean X & SD & P Value \\
\hline 1 & Case $\left(\mathrm{n}_{1}-31\right)$ & 1.315 & 0.1792 & $<0.001$ \\
\hline 2 & Control $\left(\mathrm{n}_{2}-60\right)$ & 0.7 & 0.075 & \\
& & & & \\
\hline
\end{tabular}

Fluoride level of blood is significantly high in case group than in control group.

Table 8: Comparative study of fluoride level in bone between case and control.

\begin{tabular}{|c|c|c|c|c|}
\hline Sl. No. & & Mean & SD & P Value \\
\hline 1 & Case $\left(\mathrm{n}_{1}-31\right)$ & 5395.51 & 2707.66 & $<0.001$ \\
\hline 2 & Control $\left(\mathrm{n}_{2}-60\right)$ & 750.00 & 125 & \\
\cline { 1 - 4 } & & & & \\
\hline
\end{tabular}

Fluoride level of bone in cases is much greater than the control group. The difference is being statistically significant.

Table 9: Distribution of cases according to X-ray findings

\begin{tabular}{|c|c|c|c|}
\hline Sl. No. & X-ray Changes & No. of Cases & Percentage \\
\hline 1 & Mild Osteopenia (OP) & 7 & 22.58 \\
\hline 2 & Osteosclerosis (OS) & 24 & 77.41 \\
\hline 3 & OS + Diaphyseal widening (DY) & 10 & 32.25 \\
\hline 4 & OS + DY + Soft tissue calcification (Stc) & 8 & 25.8 \\
\hline 5 & OS + DY + Stc + Osteophyte & 6 & 19.35 \\
\hline
\end{tabular}

The X-ray findings from the above table maximum patients have osteosclerosis. Only six patients have osteophytic changes (19.35\%).

Table 10: Distribution of the patients according to the Grading on the basis of fluoride level of bone (mg F/ kg of ASH concentration)

\begin{tabular}{|c|c|c|c|}
\hline Sl. No. & Grading & No. of cases & Percentage \\
\hline 1 & Preclinical (Pc) & 12 & 38.72 \\
\hline 2 & II. Clinical phase I (cPI) & 8 & 25.80 \\
\hline 3 & III Clinical phase II (cP-II) & 4 & 12.90 \\
\hline 4 & IV Clinical phase III & 7 & 22.58 \\
\hline
\end{tabular}




\section{ORIGINAL ARTICLE}

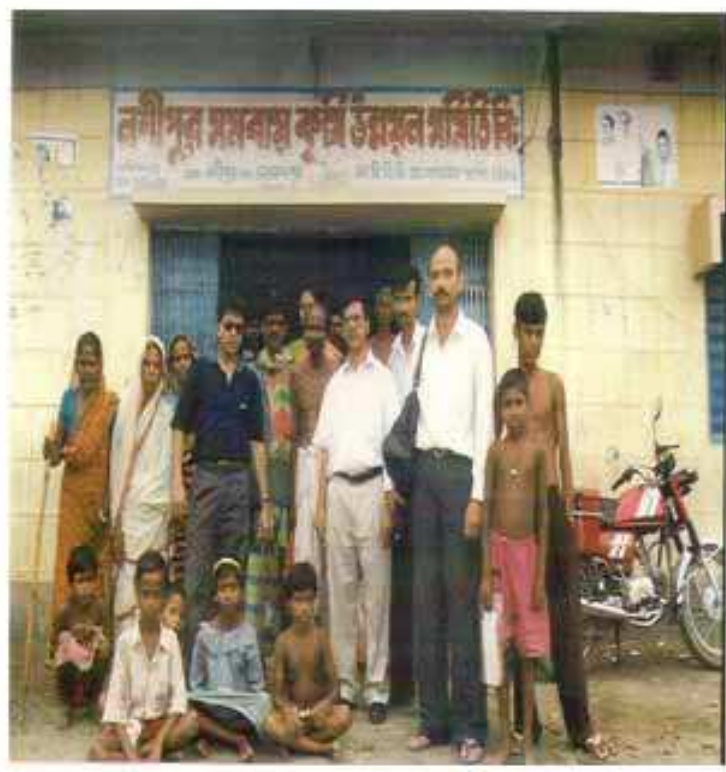

Fig1 Group of people suffering from skeletal fluorosis alog with author

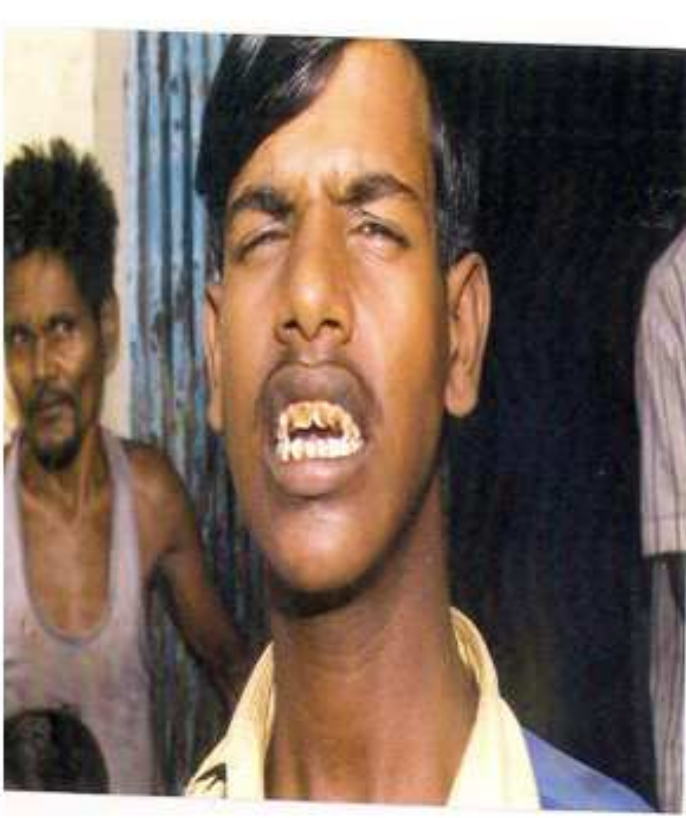

Fig 3 the patient suffering from the skeletal fluorosis

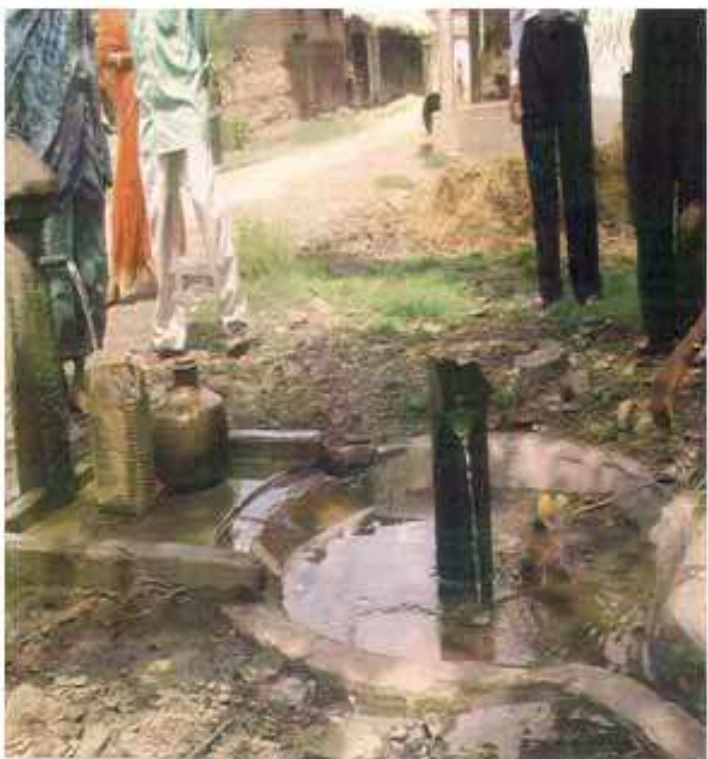

Fig 2 The culprit tub well

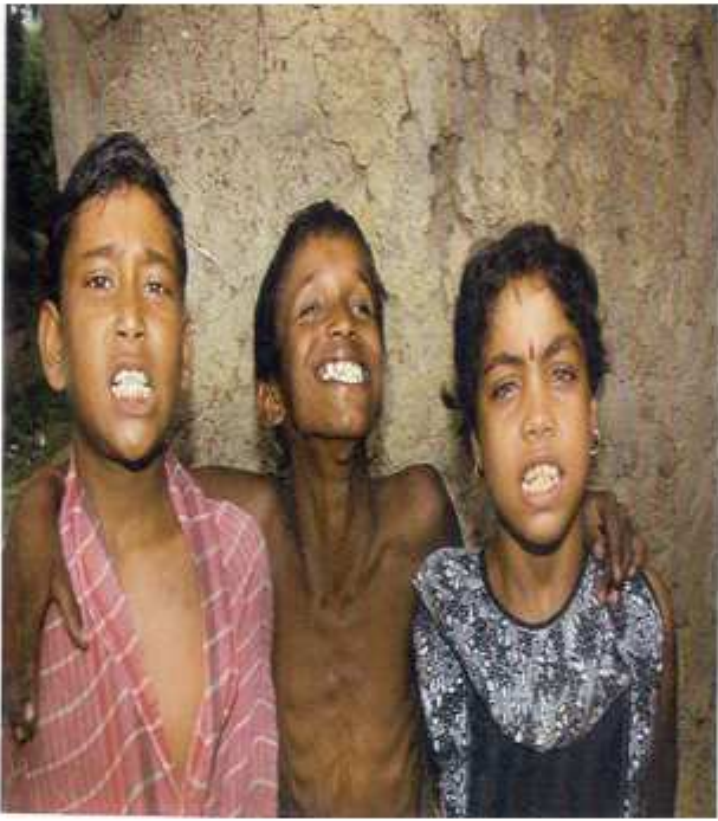

Fig 4 Group of children with dental fluorosis 


\section{ORIGINAL ARTICLE}

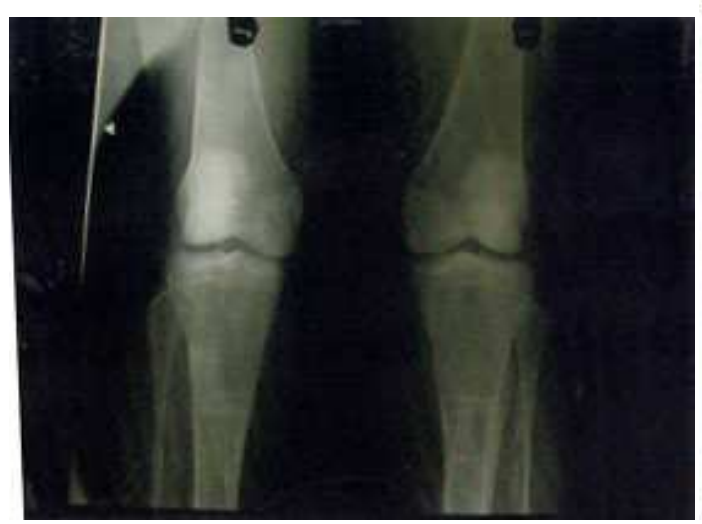

Fig 5 X-Ray of the knee of a patient with sk. Fluorosis

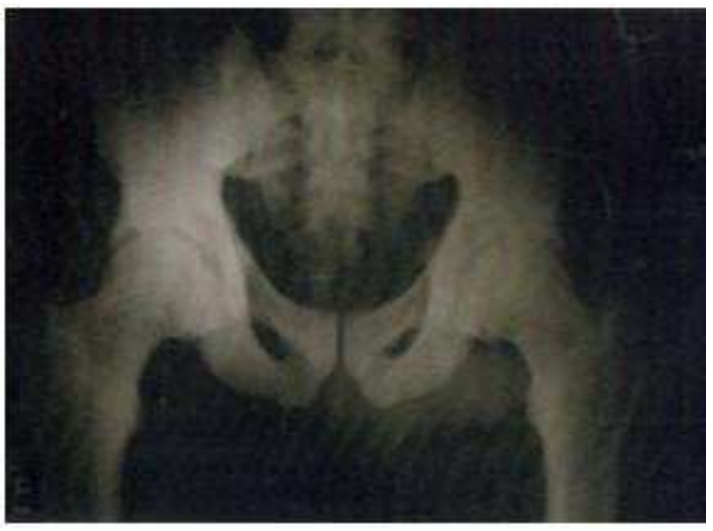

Fig $6 \mathrm{X}$ ray pelvis showing markedly sclerosis of bones

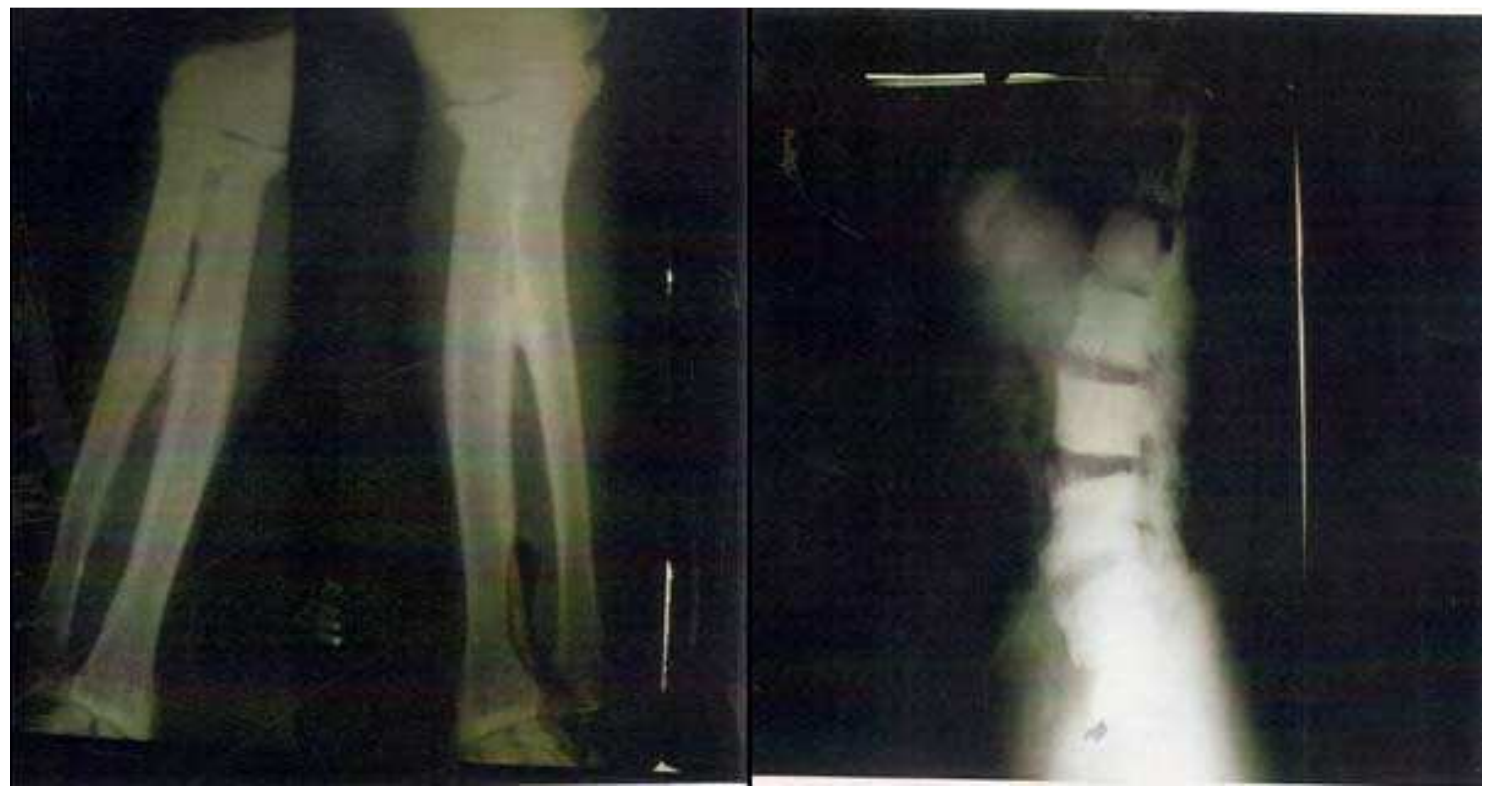

Fig $7 \mathrm{X}$ rays of hand shows the interosseous calcifications
Fig $8 \mathrm{X}$-ray of the spine lat view which showing Ant and Post longitudinal ligament calcifications 